REVISTA ANDALUZA DE ANTROPOLOGÍA

NÚMERO 15: ACTIVIDADES TURÍSTICAS, CIUDAD Y PATRIMONIO CULTURAL: MIRADAS CRÍTICAS. TOURIST ACTIVITIES, CITY AND CULTURAL HERITAGE: CRITICAL GLANCES

SEPTIEMBRE DE 2018

ISSN 2174-6796

[pp. 3-21]

http://dx.doi.org/10.12795/RAA.2018.15.01

\title{
TURISMO Y CARNAVAL: ESTUDIO SOBRE LOS IMPACTOS EN EL PATRIMONIO CULTURAL DE LA CIUDAD DE NATAL/RN (BRASIL)
}

\section{TOURISM AND CARNIVAL: STUDY ON THE IMPACTS ON THE CULTURAL HERITAGE OF THE CITY OF NATAL / RN (BRAZIL)}

Fernando Manuel Rocha da Cruz

Universidad Federal do Rio Grande do Norte (Brasil)

\section{Resumen.}

Natal es conocida como la ciudad del "sol y mar", siendo reconocida sobre todo por sus playas y clima, con temporadas turísticas durante todo el año. Se sitúa en el nordeste brasileño y es la capital del estado de Rio Grande do Norte (RN). Se trata de una ciudad con una población estimada en 885.180 habitantes (2017) que recibió el año 2018 cerca de 124.300 turistas durante el Carnaval. Esta ciudad, después de un período de estancamiento en las celebraciones de Carnaval, ganó de nuevo la visibilidad con la programación que se ha presentado. El Carnaval Multicultural de Natal, en 2018, fue organizado en ocho polos (culturales) urbanos - Ponta Negra, Redinha, Petrópolis, Centro Histórico, Ribeira, Rocas, Playa de los Artistas y Nazaré - y con varias actividades culturales, donde destaca especialmente la expresión musical. La investigación que aquí traemos, busca problematizar y reflexionar sobre el Carnaval, en la ciudad de Natal, 
como expresión compleja del patrimonio cultural inmaterial, y su relación con el turismo contemporáneo. Para ello, presentamos los resultados de una investigación cualitativa, realizada en 2018, con diversos actores sociales.

\title{
Palabras clave.
}

Carnaval, Natal (RN), patrimonio cultural inmaterial, turismo.

\begin{abstract}
.
Natal is known as the city of "sun and sea", being sought mainly for its beaches and climate, throughout the year. It is located in the Brazilian northeast and is the capital of the state of Rio Grande do Norte (RN). It is a city with a population estimated at 885,180 inhabitants (2017) that received about 124,300 tourists at the Carnival of 2018. This city, after a period of stagnation in the celebrations of Carnival, gained again visibility with the programming that has presented. The Multicultural Carnival of Natal, in 2018, was organized in eight urban (cultural) poles - Ponta Negra, Redinha, Petrópolis, Historical Center, Ribeira, Rocas, Artists Beach and Nazaré - and with several cultural activities, with highlight for the music. The research that we bring here, seeks to problematize and reflect on the Carnival, in the city of Natal, as a complex expression of intangible cultural heritage, and its relationship with contemporary tourism. For this, we present the results of a qualitative research, conducted in 2018 , with various social actors.
\end{abstract}

\section{Key words.}

Carnival, Natal (RN), cultural heritage, tourism.

\section{INTRODUCCIÓN}

Natal es la capital del estado de Rio Grande do Norte (RN), en el nordeste brasileño, con una población estimada de 885.180 personas, en 2017 (Ibge, 2018). El estado del RN recibe anualmente dos millones de visitantes nacionales y extranjeros y sus principales atracciones son naturales, destacando entre ellas el mayor árbol de caju del mundo y cerca de veinte playas con paisajes "paradisíacos" (Setur, 2018).

En los últimos años, la inversión pública y la visibilidad del Carnaval en la ciudad de Natal ha ido creciendo, atrayendo a turistas y residentes que en años anteriores iban a otras ciudades como Olinda y Recife, en el estado de Pernambuco, la ciudad de Salvador, en el estado de Bahía, todas en el nordeste brasileño, o incluso la ciudad de Río de Janeiro, en el estado con el mismo nombre. Otras opciones para celebrar el Carnaval en Rio Grande do Norte, fueron las ciudades de Areia Branca, Macau y Caicó. 
El Carnaval como patrimonio cultural tiene que ver con el modo de representación simbólica de la cultura y, en particular con los procesos de selección, negociación y delimitación de los significados. Por eso, no puede incluir todo lo que se crea en términos culturales y la "recuperación patrimonial" puede llevar al "estatismo" de la dinámica de los procesos culturales. El cambio es uno de los elementos de la cultura y del patrimonio cultural y, por consiguiente, es inherente a estos conceptos (Pereiro, 2003).

El patrimonio cultural no es, por tanto, “espontáneo o natural”, en palabras de Prista (2013), sino que resulta de una construcción simbólica, utilitaria y es objeto de identificación de un grupo social, en determinado tiempo y espacio. El pasado es entonces reconstruido, en los términos anhelados por el presente (Lowenthal, 1985).

El propio desarrollo puede basarse en el patrimonio. En ese sentido, Támaso (2005) afirma que si antes el patrimonio era un obstáculo al desarrollo, actualmente está en su origen. Como concluye la misma autora, de acuerdo con la Organización de las Naciones Unidas para la Educación, la Ciencia y la Cultura (UNESCO), "moderno es ser antiguo" (Tamaso, 2005).

Considerando lo anterior, nuestra investigación tiene por objetivo problematizar y reflexionar sobre el Carnaval, en la ciudad de Natal, como expresión compleja del patrimonio cultural inmaterial, y su relación con el turismo contemporáneo. Para ello, desarrollamos una investigación cualitativa con ocho entrevistas semiestructuradas ${ }^{1}$ aplicadas a un gestor público, un productor cultural, un responsable de un bloque de calle, un participante en una banda de frevo y cuatro participantes de los festejos de Carnaval Multicultural de Natal. De modo complementario, nos apoyamos en los resultados del estudio de la Federación del Comercio de Rio Grande do Norte, sobre el perfil de los participantes (2015-2018).

El enfoque metodológico que proponemos, en la investigación, es, como dijimos, cualitativo, entendiendo éste, como el proceso de indagación en que el investigador construye un caso complejo, holístico, bien a través del discurso, bien de representaciones, en el contexto del trabajo de campo (Creswell, 1994). La investigación sobre su naturaleza es una investigación básica que pretende crear nuevos conocimientos. En cuanto a los objetivos, es una investigación exploratoria que pretende proporcionar mayor aproximación al problema, con el fin de hacerlo más explícito. En cuanto a los procedimientos, es un estudio de caso, en el que buscamos conocer en profundidad lo que se entiende ser único y, por lo tanto, descubrir lo que tiene de característico y único (Fonseca, 2002).

1. Agradecimiento especial a las alumnas con beca de iniciación científica de la UFRN, Lígia Lima y Jasmine Medeiros, por haber recogido las entrevistas y haber procedido a su transcripción. 
De este modo, en primer lugar, se contextualizará históricamente el Carnaval, en la ciudad de Natal, para luego presentar las principales características y datos estadísticos de su Carnaval Multicultural (2015-2018). Posteriormente, presentaremos las percepciones sobre el evento, tanto de quien tiene la responsabilidad política y de organización, como de quien participa entre el público, en diferentes polos de la ciudad. Finalmente, se presenta una reflexión y un posicionamiento crítico a respecto del Carnaval Multicultural de Natal como patrimonio cultural inmaterial y su relación con el turismo.

\section{BREVE RESEÑA HISTÓRICA}

En Brasil, el término Carnaval se remonta a mediados del siglo XIX, ya que hasta entonces, según Cascudo (2012), fueron las carnestolendas las que se celebraron en términos populares, desde la llegada de los portugueses en el siglo XVI. En palabras de Cascudo: "El título real con que lo recibimos fue las carnestolendas, anunciando la venida ascética de la Cuaresma y la despedida sonora de la carne, con el Miércoles de Ceniza, de arrepentimiento expreso y pasajero" (Cascudo, 2012).

Las carnestolendas eran celebradas por las poblaciones con una profusión de sentimientos y emociones, asumiendo un carácter "tumultuoso, glotón, insaciable, despejado de maneras, violento, $[\ldots]$ confianza, intimidad, deseo de participación colectiva, fusión de todas las clases, niveles sociales, [...] las distancias culturales y de poder "(Cascudo, 2012). Se trataba, por eso, de un fenómeno colectivo, sin asumir el carácter de organización, donde la libertad individual era el mote para la celebración. La inversión de los valores de la vida cotidiana era el lema en esta fiesta que en las palabras de Cascudo (2005), se revelaban en una "licencia tácita para todo".

Es sólo, a mediados del siglo XIX, con la "fiesta imperial" de Napoleón III, que las carnestolendas se modifican. En este sentido, surgen los "coches alegóricos, normalmente satíricos al gobierno de Su Majestad, el bal masqué, las" fantasías "originales, repitiendo los modelos de París" (Cascudo, 2012). Con este nuevo ciclo surge el Carnaval y Cascudo lo describe del siguiente modo: "Así, las danzas de Carnaval surgen más sorprendentes cuando el siglo desciende hacia el final; el Velho, el Siri Congado, Corta-Jaca, solo una marcha rítmica por zabumbas de Zé Pereira, sonido intencional de la batería en el norte de Portugal, y los primeros clubes, las evoluciones finales en las calles, presentándose o despidiéndose, gorra, pantalón blanco, camisa de color fina, estandarte en el frente, guión del desfile, guiada por la aptitud del "hombre de la meta"' (Cascudo, 2012).

El Carnaval pasa a ser organizado con coches alegóricos, bailes enmascarados, crítica social y política, fantasías y canciones. Así lo ilustra Nóbrega: “Fue, [...] con el siglo XIX 
que las carnestolendas comenzaron a perder espacio. La corte tomó parte y, así, se buscaba sustituir los excesos de las carnestolendas, considerados como ejemplo de incivilidad e indignos de un país independiente. Se prefiere la modernidad francesa. Es en esa época, por lo tanto, que empiezan los grandes bailes carnavalescos" (Nóbrega, 2012).

En 1877, existe el registro de un desfile de coches representando a la élite de la ciudad, en el barrio tradicional de la Ribeira. La calle fue perdiendo cada vez más espacio como lugar de bromas jocosas, música y danza espontáneas y populares. Sin embargo, grupos étnicos como los indígenas aprovechan este período para festejar, mostrando sus ritos (Diniz, 2018).

En la década de 1930, el barrio de las Rocas se convertirá en la cuna del samba natalense, con la instalación de las principales escuelas del género: Balanço do Morro, Malandros do Samba, Asa Branca y Batuque do Morro. En las décadas de 1940 y 1950, Natal vivió el auge de sus tradicionales bailes de Carnaval (Diniz, 2018).

En la década de 1910, surgieron las tribus de indios influenciadas por los estados de Paraíba y Pernambuco. La tribu más antigua es la de los Potiguares que desfila desde 1919. El auge de las tribus fue verificado en dos momentos: década de 1930 y entre 1961 y 1964. En 2012, además de la tribu de los Potiguares, existían las tribus Comanches, Tapuios, Tabajaras, Tupinambas, Gaviones Amarillos, Tupí-Guaraníes y Guaracis (Torquato, 2012).

Entre las décadas de 1960 y 1970, surgen los desfiles o bloques en remolques tirados por tractores. En 1978, surge el bloque "Psyu", del barrio del Romero que en 2012, era el único del género. En la década de 1970 y principios de 1980, surgen los bloques Eter-na-mente, en el barrio de la Redinha, y bandas como Bandagália, en el barrio de Petrópolis que poco tiempo después, se convierte en bloque de los intelectuales y obtuvo una elevada adhesión (Torquato, 2012). Sobre los bloques de élite constituidos en esta época, Marcos de Sá Paula, del Bloque Submarino Amarillo, explica: "el bloque de élite era [...] una clase de muchachos y muchachas adolescentes que se juntaban y vendian joyas, pagaban una cantidad de dinero $\mathrm{X}$ y con ese valor contrataba una banda pequeña de seis músicos. [...] Durante el día, de 10h a 22h, ellos hacían los "asaltos" y ¿qué eran los "asaltos"? Era ir a la casa de un miembro del grupo, entonces el asalto de 10h al mediodía el sábado de carnaval va a ser en mi casa... Entonces su padre y su madre preparaba la casa, allí llegaban y hacían una fiesta allí, el personal daba la bebida. El almuerzo va a ser en la casa de otro, allí salen en una alegoría y se iban a otra casa. Eso era una cosa muy interesante 
porque no existía en el canto ninguno de Brasil ese tipo de manera de jugar carnaval" (Marcos de Sá Paula, entrevista del 23 de abril de 2018)2.

Pero el Carnaval de 1984 quedó marcado por la Tragedia del Baldo. Un autobús descontrolado, en la subida de la Avenida Rio Branco, causó 19 muertos. La escasez de las inversiones públicas, la falta de seguridad y la tragedia del Baldo alejaron los participantes y casi acabó con el Carnaval de calle, en Natal. Las personas pasaron a preferir la seguridad de las playas. En ese período, se destacó la playa del Pirangi del Norte (Torquato, 2012).

En consecuencia, casi todos los bloques de Natal desaparecieron. Excepción para Psyu y las Kengas, este último, surgido en 1983, dentro del Bandagália. A partir de la década de 1990, surgieron otros bloques, pero no todos resistieron mucho tiempo. Se destacan los bloques "Baiacu en la Vara" (1990), en la Redinha; "Poetas, Carecas, Brujas y Hombres lobo" (2004), en Ponta Negra; "Carnapetinga" (2007), en el Conjunto Santarém que aún hoy promueven el Carnaval en la ciudad de Natal. Por último, es de importancia mencionar la resistencia del bloque de "mela-mela" denominado "Los Perro"3 (1962), del barrio de la Redinha. Los juerguistas de este bloque, "los Perro", se juegan y cubren de lodo, en el manglar de la Redinha (Torquato, 2012). Sobre el bloque de las Kengas, añade Marcelo Veni, productor cultural: "El bloque de las kengas [...] fue creado por el productor Lula Belmont y un conjunto de amigos intelectuales y artistas que aún en 93 crearon un bloque para animar el centro histórico de la ciudad. [...] La temática de ese bloque era el hombre vestido de mujer, y aún es, la broma de la kenga. Entonces entré en 97 para hacer apoyo de producción y en ese tiempo la gente fue participando y sumando en el mantenimiento del bloque dentro del carnaval potiguar. Hoy hago parte del directorio y de la producción, y es un proyecto que dentro del Carnaval es muy divertido realizar por la temática y la aceptación popular que tiene, desde el niño al anciano, que juega con esa cuestión de la alegoría de hacerse un gran teatro en medio de la calle y principalmente mantener el centro de la ciudad viva el domingo de carnaval" (Marcelo Veni, entrevista de 8 de mayo de 2018).

\section{CARNAVAL MULTICULTURAL DE NATAL}

En el año 2013, el Ayuntamiento de Natal, a través de la Fundación Cultural Capitania

2. "[...] algunos bloques [de élite] comenzaron a crecer demasiado, de 40 a 50 componentes de aquí a poco estaban con 200, 250 porque los presidentes de los bloques comenzaron a percibir que era una fuente de ingresos. [...] ¿qué pasó? Nadie quería recibir más. ¿Quién recibirá a 250 personas en su casa? Entonces ellos alquilaban un espacio, un club/lugar y se quedaban allí y luego, de noche iban al club. Para América, para el ABC, para los clubes que tenían en la ciudad, que tenían baile. [...] A partir de ahí comenzó a surgir las bandas, ahí tenía a Bandagália, que fue la primera banda así, que fue grande de músico que salía en medio de la calle como sucedía en Olinda "(Marcos de Sá Paula, entrevista del 23 de marzo abril de 2018).

3. "Los perro" se utiliza con el nombre en singular y la ausencia de concordancia gramatical. 
de las Artes (FUNCART) promovió la 5a edición del Carnaval Multicultural de Natal, en cinco polos de la ciudad, en particular, Ponta Negra, Ribeira, Cidade Alta, Alecrim e Redinha. En este, desfilaron por la ciudad casi treinta bloques al sonido de las orquestas de frevo contratadas por FUNCART. En total, fueron contratados 400 músicos de 19 orquestas. La fiesta contó con tres conciertos musicales. El Ayuntamiento dio apoyo financiero de 500 mil reales a la organización del evento (Outeda, 2013). En 2014, el Ayuntamiento de Natal invirtió 6 millones de reales mientras que en 2017 y 2018, el apoyo financiero concedido fue de 4,5 millones de reales y 5,5 millones de reales, respectivamente, con recursos públicos y de la iniciativa privada, a través del patrocinio o resultado de la renuncia fiscal por la Ley Rouanet y la Ley Djalma Maranhão (Lopes, 2017; Giovanni, 2018). En 2017 y 2018, fueron contratados más de 1500 músicos (Natal, 2018a; Natal, 2018b; Fecomercio RN, 2017).

El 10 Carnaval Multicultural de Natal (2018) contó con doce días de programación y ocho polos carnavalescos (Ponta Negra, Redinha, Petrópolis, Centro Histórico, Ribeira, Rocas, Playa de los Artistas y Nazaré en la Zona Oeste). Las llamadas públicas del Ayuntamiento de Natal, a través de la Secretaría Municipal de Cultura, privilegió las siguientes áreas/ especialidades: Tribus de indígenas, Escuelas de Samba, atracciones musicales, bandas de frevo; bloques; Trozas y Virada Carnavalesca ${ }^{4}$. Es importante destacar que según el Alcalde de Natal, el 95\% de la programación contó con artistas de Natal (véase Tabla 1).

Tabla 1 - Principales atracciones nacionales y locales, del Carnaval de Natal 2018

\begin{tabular}{|c|c|}
\hline Atracciones nacionales & Atracciones locales \\
\hline Carlinhos Brown & \\
Sandra de Sá & Sueldo Soares y Banda \\
Renata Arruda & Isaque Galvão \\
Eduardo Dusek & DuSouto \\
Monobloco & Laryssa Costa \\
Roberta Sá & \\
Ricardo Chaves & \\
Spok Frevo & \\
\hline
\end{tabular}

Fuente: Elaboración propia.

4. La acción VIRADA CARNAVALESCA tiene por finalidad: 1.1 Contribuir con la descentralización de la programación del Polo Ponta Negra, del Carnaval Multicultural de Natal 2017, permitiendo la iniciativa de programación que contribuya con el acceso de la población a las Atracciones Musicales Diversas en la orilla de la referida playa. 1.2 Permitir la promoción de las Atracciones Musicales locales diversas, junto al gran público frecuentador de la Playa de Ponta Negra. 1.3 Establecer una oportunidad para el aumento del flujo de turistas, permitiendo una programación diversa, ecléctica y orientada a la promoción de la diversidad musical característica de los actuales carnavales contemporáneos (Portaria nº 007/2017 - GP / FUNCARTE de 26 de enero de 2017). 
La investigación realizada por el Instituto de Investigación y Desarrollo del Comercio de la Federación de Comercio de Bienes, Servicios y Turismo del Estado de RN (IPDC/ Fecomércio RN $)^{56}$, trazó el perfil de los participantes del Carnaval Multicultural de Natal en 2018 y detalló los gastos realizados por los participantes durante la fiesta.

De este modo, en 2016, se observa un aumento de público del Carnaval en Natal del $20,62 \%$ frente a 2015 y en 2017 un nuevo aumento del 15,56\% con respecto al año anterior. En 2018, el aumento con respecto a 2017, fue del 26,49\%. Sin embargo, en cuanto al movimiento financiero existe un descenso del 27,78\% de 2016 frente a 2015 y un crecimiento del 3,33\% y del 52,36\% con respecto a 2017 y 2018 , respectivamente, con relación a los años inmediatamente anteriores (véase Tabla 2).

En 2018, el público era mayoritariamente de Natal con una tasa del 78,3\%. Los turistas se cifraron en el $21,7 \%$, de los cuales el $99,1 \%$ eran brasileños y el $0,9 \%$ extranjeros (Fecomercio RN, 2018).

Tabla 2: Público estimado y movimiento financiero en el Carnaval de Natal (2015-2018)

\begin{tabular}{|l|c|c|c|c|}
\hline & $\mathbf{2 0 1 5}$ & $\mathbf{2 0 1 6}$ & $\mathbf{2 0 1 7}$ & $\mathbf{2 0 1 8}$ \\
\hline Público & 325.000 & 392.000 & 453.000 & 573.000 \\
\hline $\begin{array}{l}\text { Movimiento } \\
\text { financiero (en } \\
\text { Reales) }\end{array}$ & 54 millones & 39 millones & 40,3 millones & 61,4 millones \\
\hline
\end{tabular}

Fuente: Elaboración propia.

El aumento del 76,31\% del público del Carnaval de Natal, entre 2015 y 2018, no es proporcional al aumento del movimiento financiero, aunque este ha aumentado en ese período temporal el 13,70\% (véase Tabla 2).

En cuanto al gasto medio diario de los participantes en el Carnaval Multicultural de Natal existe una disminución del 26,66\%, en 2016, frente al año anterior, y una recuperación del 2,14\%, en 2017, en relación a 2016. En 2017, el aumento es del 5,93\%, en relación con el 2016, en lo que se refiere a los habitantes de Natal. Sin embargo, los gastos medios diarios de los turistas vienen disminuyendo desde 2016, habiéndose registrado un retroceso del $3,51 \%$, frente al año anterior. En lo que se refiere a 2017 y 2018, los gastos disminuyeron

5. Se realizaron 601 entrevistas, en el período de 23 a 28 de febrero de 2017, en todos los polos del evento (Fecomércio RN, 2017).

6. Se realizaron 702 entrevistas, en el período del 08 al 14 de febrero de 2018, en los locales de atracciones del Carnaval de Natal (Fecomércio RN, 2018). 
un $25,26 \%$ y un $44,31 \%$ con respecto a los años inmediatamente anteriores (véase Tabla $3)$.

Tabla 3: Gasto medio diario de los participantes (2015-2018)

\begin{tabular}{|l|c|c|c|c|}
\hline & $\mathbf{2 0 1 5}$ & $\mathbf{2 0 1 6}$ & $\mathbf{2 0 1 7}$ & $\mathbf{2 0 1 8}$ \\
\hline $\begin{array}{l}\text { Habitantes de } \\
\text { Natal }\end{array}$ & $\mathrm{R} \$ 82,12$ & $\mathrm{R} \$ 60,23$ & $\mathrm{R} \$ 61,52$ & $\mathrm{R} \$ 65,17$ \\
\hline Turista & $\mathrm{R} \$ 295,67$ & $\mathrm{R} \$ 285,26$ & $\mathrm{R} \$ 213,20$ & $\mathrm{R} \$ 118,73$ \\
\hline
\end{tabular}

Fuente: Elaboración propia.

Entre el 2015 y el 2018, la disminución del 20,64\% del gasto medio diario de los participantes de Natal, es bastante inferior a la registrada en relación a los turistas (59,84\%) (véase Tabla 3$)$.

El público del Carnaval Multicultural de Natal es en su mayoría del sexo masculino con valores de 55,9\%, 58,2\%, y 50,4\%, en 2016, 2017 y 2018, respectivamente. En cuanto a las franjas de edad, destacan las franjas de los 25 a los 34 años, con el 27,1\%, en 2018 (29,1\%, en 2017 y 34,2\%, en 2016) y de los 45 a los 59 años, con 22,8\%, en 2018 (25,3\%, en 2017 y el 20,4\% en 2016) (véase Tabla 4).

Tabla 4: Público masculino

\begin{tabular}{|l|c|c|c|}
\hline & $\mathbf{2 0 1 6}$ & $\mathbf{2 0 1 7}$ & $\mathbf{2 0 1 8}$ \\
\hline Hombres & $55,9 \%$ & $58,2 \%$ & $50,4 \%$ \\
\hline $\begin{array}{l}25 \text { a 34 años } \\
\text { (nativos) }\end{array}$ & $34,2 \%$ & $29,1 \%$ & $27,1 \%$ \\
\hline $\begin{array}{l}45 \text { a 59 años } \\
\text { (nativos) }\end{array}$ & $20,4 \%$ & $25,3 \%$ & $22,8 \%$ \\
\hline
\end{tabular}

Fuente: Elaboración propia.

En 2018, la participación del público femenino $(49,6 \%)$ casi iguala el porcentaje de la participación masculina (50,4\%), lo que indica el aumento de la participación femenina en las actividades de Carnaval de Natal, en relación a los años anteriores (cf. Tabla 4). 
En la encuesta, el 32,3\% y el 24,2\%, para 2018 y 2017, respectivamente, respondieron que el principal interés eran las atracciones musicales. Sin embargo, participaron en el Carnaval de Natal el 15,3\% y el 15,7\%, de los entrevistados en la ciudad para ahorrar, en 2017 y en 2018, respectivamente (Fecomercio RN, 2017; Fecomercio RN, 2018).

Otros intereses o motivaciones identificados para la participación en el Carnaval de Natal de 2018 fueron: alegría/animación (18,1\%), fiestas gratuitas en las calles $(16,7 \%)$, playas de la ciudad (14\%), organización y estructura (5\%), conveniencia (5\%), familia/amigos (5\%), proximidad/localización (3,7\%) y tranquilidad (2,7\%) (véase Tabla 5).

Tabla 5: Principal interés/motivación en el Carnaval Multicultural de Natal (2018)

\begin{tabular}{|l|c|}
\hline \multicolumn{1}{|c|}{ Interés/Motivación } & $\mathbf{2 0 1 8}$ \\
\hline Conciertos musicales & $32.3 \%$ \\
\hline Alegría/animación & $18,1 \%$ \\
\hline Fiestas gratuitas en las calles & $16,7 \%$ \\
\hline Situación financiera & $15,7 \%$ \\
\hline Playas de la ciudad & $14 \%$ \\
\hline Organización y estructura & $12,7 \%$ \\
\hline Conveniencia & $5 \%$ \\
\hline Família/amigos & $5 \%$ \\
\hline Proximidad/ localización & $3,7 \%$ \\
\hline Tranquilidad & $2,7 \%$ \\
\hline
\end{tabular}

Fuente: Elaboración propia.

\section{PERCEPCIONES SOBRE EL CARNAVAL MULTICULTURAL DE NATAL}

Para la gestión pública del Ayuntamiento de Natal el Carnaval de la ciudad forma parte de los festejos populares, siendo por ello una fiesta tradicional que integra el calendario cultural y forma parte del patrimonio cultural inmaterial de la urbe. En los últimos años, se ha producido un aumento de la inversión pública en el Carnaval para promoverlo como fiesta tradicional. Reflejo de ello, es que la conexión de los bloques carnavaleros fue elegida como tema en el discurso político, tras haber sido interrumpida en los años ochenta debido a la tragedia del Baldo y a la muerte de casi dos decenas de componentes del bloque "El Cordón del Puxa-Saco". El "estancamiento" del Carnaval de Natal se debió 
al abandono del anterior dinamismo de ese bloque y otras bandas en la programación “espontánea” del Carnaval.

El aumento de la popularidad de los bloques carnavaleros y el entendimiento de que la ciudad podría “jugar de manera un poco más tranquila”, llevó al Ayuntamiento a apoyar financieramente el Carnaval. Complementariamente, se decidió la contratación de atracciones nacionales para atraer más público. En relación a las atracciones artísticas locales, fueron efectuadas a través de licitaciones públicas.

La promoción de un Carnaval Multicultural corresponde, en la visión de la gestión pública, al reconocimiento de la diversidad existente en la ciudad, a partir del diálogo con asociaciones de carnaval, teniendo como consecuencia la creación de polos en la ciudad. Como describe Josenilton Tavares, Director de Políticas Culturales de la Secretaría Municipal de Cultura de Natal: "Nosotros teníamos el desfile de las escuelas de samba como tradición. [...]. Cada año teníamos realmente esos desfiles allí en la Ribeira, que es una de las escuelas de samba y las tribus de indígenas, pero aún de manera muy tímida. Los bloques se desvanecían, porque una parte de los participantes con condiciones económicas viajaban a Recife o Salvador que eran los carnavales más comerciales. Pero, quedaba sí una parte muy pequeña pero considerable de personas que jugaba en los barrios y en algunos lugares" (Josenilton Tavares, entrevista de 18 de abril de 2018).

Los territorios que ya poseían una programación de Carnaval y las consecuentes solicitudes de apoyo financiero, llevaron al poder público a reconocer los mismos como polos y a abrir licitaciones para apoyar sus actividades. En este proceso se destaca el polo de Ponta Negra debido a su conexión con el turismo y el polo de la Redinha que concentra las clases más populares de la población y aún por su proximidad a la Zona Norte que concentra igualmente la población de estrato social medio y bajo. En este último polo se encuentran aún algunos bloques de "tradición", es decir, con más de diez años, como "Los Perro" y "Baiacu”.

La organización en polos corresponde, por un lado, a políticas de descentralización y democratización. Por otro lado, procura evitar la concentración de la inversión pública en los grandes eventos, toda vez que entiende que es necesario atender a las políticas culturales de hecho y a la valorización del patrimonio cultural inmaterial. Además, la gestión pública considera que se debe atender la dinámica de los polos y las diferentes ediciones del Carnaval en Natal que piden respuestas inmediatas, pues cada polo tiene sus características propias. Por eso, cada año, el municipio viene mejorando la estructura de los polos dotándolos de escenario, sonido, luz, decoración, camarines, baños, tabiques con espacios reservados para el público y para los vendedores ambulantes, seguridad y movilidad de acceso. Sin embargo, se identifican algunas fragilidades por los participantes, en los polos, como las cuestiones relacionadas con la seguridad (los entrevistados Artur y Danyele) y las de la movilidad, sobre todo después del cierre de la programación en los 
polos, por la ausencia de circulación de autobuses en la ciudad (los entrevistados Artur, Keilane, Mizael y Danyele).

Sobre la estructuración en polos, Marcelo Veni, productor cultural, explica: "si yo vivo en la Zona Norte, tengo una programación de carnaval que no voy a necesitar salir a otra esquina, como a Ponta Negra. Pero si quiero salir yo también puedo ir porque los polos empiezan temprano y terminan temprano porque el carnaval de la ciudad no tiene esa tradición de dar la vuelta durante la noche, [la programación] termina alrededor de las 00h - 01h" (Marcelo Veni, entrevista de 8 de mayo de 2018).

Sin embargo, hay diferencias entre los polos, como afirma Júlio Brito, músico de banda de frevo, para quien: "[En] algunos polos no se vive realmente la cultura del Carnaval, mientras en otros reina aquella vivencia del carnaval antiguo de bloques de calle y otros tipos de atracciones "(Júlio Brito, entrevista de 30 de abril de 2018).

En cuanto a la participación de los artistas locales, el Director de Políticas Culturales considera que hay que incluir más a los grupos de cultura popular, opinión compartida por algunos participantes del Carnaval Multicultural de Natal. De momento, la gestión pública logró incluir a las tribus de indios en los polos. Y, añade: "la gente necesita realmente dar más visibilidad a la esencia de esa fiesta que son los actores míticos y el significado que ellos tienen para el carnaval. Y en el caso de que se trata de una de las más importantes, creo que eso es inevitable. Como patrimonio inmaterial es fundamental que se conmemore, que se festeje, forma parte de una simbología cultural de la sociedad. Los artistas locales están participando... Creo que es una oportunidad muy buena, se beneficia mucho" (Josenilton Tavares, entrevista de 18 de abril de 2018).

Por otro lado, las bandas de samba necesitan profesionalizarse. También es necesario tener una política para las bandas de frevo y la gestión pública debe aumentar la inversión. Así, los grupos de cultura popular necesitan prepararse para el Carnaval, ya que el retorno a los artistas es positivo y éstos poseen escenarios para poder actuar, siendo las retribuciones similares a las que se pagan en los estados de Pernambuco y Paraíba. Para Marcelo Veni, la colocación de artistas locales en polos como Ponta Negra, vino a dar mayor visibilidad a estos profesionales $y$, de ese modo, quedaron más cerca del público en general.

Los cambios percibidos en relación a las ediciones anteriores son sobre todo económicos. Hay una aproximación de la economía creativa con provecho lucrativo para algunas actividades como la de músico (instrumentista, banda de frevo e intérpretes, entre otros). $\mathrm{Y}$, aunque no posea un marketing "agresivo" como el Carnaval de Recife o Salvador de Bahía, hay cada vez más personas que se quedan en la ciudad durante la época de Carnaval. Por otro lado, hay cada vez más turistas en la ciudad, aunque sea un Carnaval de polos, donde aún están ausentes los corredores y los itinerarios. Por último, hay que 
subrayar el interés creciente de los empresarios en los bloques de los grupos sociales privilegiados, que se vienen organizando y saliendo en la Plaza Cívica.

De este modo, los principales impactos del Carnaval de Natal son sobre todo económicos y los podemos ejemplificar con los ingresos obtenidos por los artistas, profesionales de producción, técnicos, proveedores de servicios, organizadores de eventos y comercio informal. Como señala Marcos de Sá Paula, responsable del bloque Submarino Amarillo: "En el propio [bloque] Submarino Amarillo, hubo gente que se quedó haciendo unas diademas que era con aquellos periscopios. Tiene hasta un vídeo [...]. Es decir, termina generando renta para quien trabaja con costura, comercio que vende máscara, que vende confeti, serpentina. De una cierta forma tiene un incremento en el comercio de los artesanos" (Marcos de Sá Paula, entrevista de 23 de abril de 2018).

En cuanto a los impactos sobre el patrimonio cultural inmaterial, por tratarse de un evento tradicional y de gran porte, es preciso relevar la dimensión creativa del Carnaval, es decir, los realizadores "aquel que coloca el bloque en la calle, la escuela de samba, ese valorizar artístico humano", y los artistas, según Marcelo Veni. Además, hay una valorización del centro histórico, con su historia y arquitectura. Este productor cultural, destaca las "kengas" y la escuela de samba, como patrimonio cultural inmaterial, en el marco del Carnaval.

La política cultural no puede reducirse al apoyo de los grandes acontecimientos, aunque estos den más oportunidades para los artistas locales, en el marco del patrimonio cultural inmaterial. En ese sentido, la ciudad necesita políticas públicas continuas que no se limiten a este gran evento que es el Carnaval.

El Carnaval es importante para la ciudad de Natal, por su capacidad de atracción turística, por lo que una preparación oportuna y el diálogo con el sector turístico son esenciales para su pleno éxito. Los hoteles llenos, un gran número de taxis en circulación, la proximidad de las atracciones, la programación atractiva y la seguridad son expresiones del éxito del Carnaval Multicultural de Natal. En cuanto a la seguridad, Josenilton Tavares observa: "Sin contar que sólo tuvimos una incidencia en el carnaval, incidencia seria, usted no tiene ese impacto de sentirse inseguro en los polos y mira que Natal tenía una fama un poco negativa con respecto a eso y siempre tuvimos un carnaval muy tranquilo y eso está muy bien. [...] Todo el mundo se fue a las calles. Las calles estaban llenas y no es broma, si tienen hasta foto de drone ... Tiene el polo de las Rocas y no ha sucedido nada. Yo coordiné el polo de la Ribeira de escuela de samba que tuvo alrededor de 5.000 personas y no sucedió nada. Redinha con 40 mil personas y lo que hubo fueron algunos hurtos, cosas esporádicas... Desafortunadamente, hubo un intento en el bloque de los kengas. Había una multitud y un ciudadano que era policía fue defender y se produjo 
un intercambio de disparos porque el chico reaccionó en el momento pero la guardia nacional [...] tomó al hombre a la hora" (Josenilton Tavares, entrevista de 18 de abril de 2018).

El Carnaval muestra la habilidad organizativa de Natal. En consecuencia, consigue captar turistas en esta época y atraer residentes con esa oferta cultural y lúdica en la que los turistas pueden conciliar la ida a la playa con la noche, donde pueden participar en los festejos de Carnaval. Sin embargo, el Carnaval de Natal no está consolidado a nivel nacional, como los de Río de Janeiro, Olinda, Recife o Salvador.

El crecimiento del Carnaval, en los últimos años, exige del poder público una cuidadosa planificación. De ahí que la participación de los ciudadanos de Natal en los festejos de Carnaval debe transitar de la "desconfianza hacia la confianza", según el Director de Políticas Culturales del municipio de Natal. Para Marcos de Sá Paula, del bloque Submarino Amarillo, el polo de Ponta Negra tiene un "atractivo más turístico" mientras, por ejemplo, el polo de Petrópolis atrae sobre todo, ciudadanos de Natal. De modo que ese interés de participación en el evento pasa, por un lado, por el reconocimiento de la diversidad cultural de la ciudad y, por otro, por el deseo o aspiración en contribuir al propio proceso de planificación del evento.

\section{CONSIDERACIONES FINALES}

El patrimonio cultural inmaterial es la "construcción" del pasado en el presente, o sea, es el resultado de una selección de elementos culturales del pasado en la contemporaneidad. Así, el Carnaval Multicultural de Natal ya no es la libre expresión de la cultura popular que se vivió en la ciudad hasta mediados del siglo XIX, pero si se puede considerar un evento cultural y político promovido y apoyado logística y financieramente en la actualidad por órganos políticos municipales en particular la Secretaría Municipal de Cultura de Natal.

De este modo, el Carnaval Multicultural de Natal se puede entender como un mosaico constituido por diferentes expresiones musicales, culturales y artísticas que pasan desde las exhibiciones de las tribus de indios, a la música de los bloques carnavaleros, a la danza de las escuelas de samba, a la música y danza de las bandas de música frevo y las actuaciones en los espectáculos musicales con artistas nacionales y locales. Este resultado se debe a la reunión de diferentes elementos culturales que se introdujeron, en diferentes momentos histórico-culturales en la ciudad, desde finales del siglo XIX hasta principios del siglo XXI, fruto de las injerencias políticas y de la regulación social del Carnaval de Natal. Y si las tribus de indios comenzaron en la década de 1910, las escuelas de samba se remiten a la década de 1930 mientras los bloques se afirman a partir de la década de 1970. Estas son tres manifestaciones culturales presentes en el Carnaval de Natal, en la actualidad. Además, la propia clasificación de los bloques de "tradición" resulta de los 
mismos existieron hace al menos 10 años, lo que denota que la existencia de éstos, no deja de ser breve.

La organización política y cultural del Carnaval con fondos públicos y privados delimita, por un lado, las actividades admitidas en el evento y, por eso, deja "fuera" todas las actividades artísticas y culturales que en el entendimiento de los órganos culturales y políticos de la ciudad, no deben incluirse en la programación como es el caso, por ejemplo, de la literatura, la pintura, el teatro y los museos. Por consiguiente, el diálogo entre las asociaciones y el poder político para la democratización y la descentralización del Carnaval, en polos, pasa también por atender a las relaciones de poder entre asociaciones y su reconocimiento por el poder político, ya que es una decisión política el reconocimiento y la institución de los polos.

En los últimos años, el aumento de la inversión pública en el evento, tiene como objetivo aumentar el número de participantes en el Carnaval y, con ello, contribuir al crecimiento económico del municipio. Si por un lado, el número de participantes viene aumentando, eso se debe a la inclusión en la programación de espectáculos musicales gratuitos, con artistas nacionales y locales, sobre todo en el polo de Ponta Negra que es el barrio con más infraestructura turística, con restaurantes y hoteles. Este crecimiento se debe, no sólo, a la atracción de visitantes y turistas de estados cercanos, sino también a la atracción de ciudadanos que dejan de viajar a otros estados debido a la oferta de una programación de Carnaval.

Ponta Negra es uno de los barrios más nuevos de la ciudad que resultó del alto crecimiento urbano, sobre todo tras la instalación de una base aérea norteamericana en la ciudad durante la segunda guerra mundial. La ciudad de Natal pasó de 54,836 habitantes, en 1940, a 709.422 habitantes, en el año 2000. En 2017, la estimación es de 885.180 habitantes (Ibge, 2018; Silva, 2001).

La inserción de la Virada Cultural, a partir de 2017, en el polo de Ponta Negra resulta de la necesidad de crear más animación cultural en un barrio turístico, para atraer los turistas a ese barrio. Las cuestiones de seguridad en la ciudad no son indiferentes a la estructuración de los polos, ni siquiera la cuestión de la movilidad, a través del transporte público que no tienen horarios de circulación durante la noche que permitan a la población, así como a los turistas, disfrutar de espectáculos tranquilamente a medida que se va acercando a su final.

El modelo del Carnaval Multicultural de Natal es único en su construcción y en sus opciones políticas. Se trata de un Carnaval con influencia de los estados vecinos, como Paraíba y Pernambuco pero que presenta un modelo propio. El Carnaval de Río y las escuelas de samba no dejan de influir también en la organización del evento. 
En cuanto a la fragilidad en la oferta de transporte público durante las noches del Carnaval de Natal - a excepción del servicio de taxi - se debe, entre otras causas, a la inseguridad pública y, de esa forma, tiene el poder de fijar a los ciudadanos al polo más cerca de su residencia. Y, si en las últimas ediciones, hemos verificado la movilidad de algunas atracciones por los diferentes polos, democratizando el acceso del público, no deja de promover la espectacularización del Carnaval, a expensas de la conexión "umbilical" de las atracciones tradicionales a sus "actores" (residentes). Los espectáculos musicales con atracciones nacionales y locales vienen a popularizar el Carnaval y atraer a más visitantes y turistas, pero también hace que los participantes sean más pasivos en el sentido de esperar que los mismos sólo desempeñan el papel atribuido al público.

Por lo tanto, las políticas de profesionalización y de creación de ingresos para los artistas vienen a hacer del Carnaval, un evento en que las personas, sean ellas residentes, visitantes o turistas, puedan participar en la categoría "público", una vez que los actores del Carnaval son, sobre todo, los "profesionales".

Las asociaciones tienen, por eso, un papel fundamental en la promoción dela participación de los ciudadanos en este evento tradicional que el tiempo no deja de moldear y construir, pero siempre para desempeñar un "guión". 


\section{REFERENCIAS BIBLIOGRÁFICAS}

Cascudo, Câmara (2005) “Carnaval! Carnaval!”. En Raimundo Arrais (coord.) Crônicas de origem: a cidade do Natal nas crônicas cascudianas dos anos 20. Natal: EDUFRN, pp. 122-129.

Cascudo, Camara (2012) Dicionário do Folclore Brasileiro. São Paulo: Global

Creswell, John W. (1994) Research design: qualitative and quantitative approaches.

Thousand Oaks (California): Sage Publications.

Diniz, Emanuel (2018) “Uma breve história do Carnaval potiguar”. Som sem plugs http:// www.somsemplugs.com.br/uma-breve-historia-do-carnaval-potiguar/ [Consultado el 14 mayo de 2018].

Fecomercio RN, Federação do Comércio de Bens, Serviços e Turismo do Estado do RN (2018) “Perfil dos Foliões do Carnaval de Natal 2018” http://fecomerciorn.com.br/ pesquisas/perfil-dos-folio\%CC\%83es-do-carnaval-de-natal-2018/ [Consultado el 18 de mayo de 2018].

Fecomercio RN, Federação do Comércio de Bens, Serviços e Turismo do Estado do RN (2017) "Mais de 370 mil potiguares e de 82 mil turistas movimentaram R\$ 40,3 milhões no Carnaval de Natal 2017, dizem Fecomércio RN e Prefeitura” http://fecomerciorn.com. br/noticias/mais-de-370-mil-potiguares-e-de-82-mil-turistas-movimentaram-r-403milhoes-no-carnaval-de-natal-2017-dizem-fecomercio-rn-e-prefeitura/ [Consultado el 14 de mayo de 2018].

Fonseca, J. J. S. (2002) Metodologia da pesquisa científica. Fortaleza: UEC

G1 RN (2013) “Apesar da crise, Prefeitura de Natal gastará R\$ 500 mil com carnaval”. Potiguar Notícias http://www.potiguarnoticias.com.br/noticias/21430/apesar-da-criseprefeitura-de-natal-gastara-r-500-mil-com-carnaval [Consultado el 14 de mayo de 2018].

Giovanni, Bruno (2018) "Pesquisa Fecomércio sobre o Carnaval de Natal aponta crescimento de 26,7\% no público da festa”. Blog do Bruno Giovanni https://www. blogdobg.com.br/pesquisa-fecomercio-sobre-o-carnaval-de-natal-aponta-crescimentode-267-no-publico-da-festa/ [Consultado el 20 de mayo de 2018].

Giovanni, Bruno (2017) "Prefeitura divulga programação do Carnaval Multicultural de Natal 2017; confira”. Blog do Bruno Giovanni https://www.blogdobg.com.br/prefeituradivulga-programacao-do-carnaval-multicultural-de-natal-2017-confira/ [Consultado el 14 de mayo de 2018].

Ibge, Instituto Brasileiro de Geografia e Estatística (2018) "Natal”. Ibge Cidades https:// cidades.ibge.gov.br/brasil/rn/natal [Consultado el 14 de mayo de 2018]. 
Lopes, Cinthia (2017) "O Carnaval voltou para nunca mais ir embora". Tribuna do Norte http://www.tribunadonorte.com.br/noticia/a-o-carnaval-voltou-para-nunca-mais-iremboraa/372720 [Consultado el 14 de mayo de 2018].

Lowenthal, David (1985) The Past is a Foreign Country. Cambridge: Cambridge University Press.

Natal, Prefeitura Municipal do (2018a) "Carnaval Multicultural 2018 terá oito polos e atrações locais e nacionais" http://natal.rn.gov.br/noticia/ntc-27756.html [Consultado el 14 de mayo de 2018]

Natal, Prefeitura Municipal do (2018b) "Prefeitura apresenta atrações e planos de segurança e mobilidade para o Carnaval 2018" http://natal.rn.gov.br/noticia/ntc-27800. html [Consultado el 20 de mayo de 2018].

Natal, Secretaria Municipal de Cultura (2017) Blog da FUNCART http://www. blogdafuncarte.com.br/confira-programacao-completa-do-carnaval-multicultural-denatal/ [Consultado el 14 de mayo de 2018].

Nóbrega, Thaís Santos (2012) “Câmara Cascudo e o "Carnaval! Carnaval!": breve análise da crônica cascudiana e de perspectivas atuais do carnaval natalense". Imburana: revista do Núcleo Câmara Cascudo de Estudos Norte-Rio-Grandenses v. 3, n. 5, pp. 115-123.

Outeda, Dionísio (2013) "Programação do carnaval multicultural de Natal neste 2013". Canindé Soares - Repórter-fotográfico http://canindesoares.com/programacao-docarnaval-multicultural-de-natal-neste-2013 [Consultado el 14 de mayo de 2018].

Pereiro Pérez, X. (2003): "Patrimonialização e transformação das identidades culturais". En J. Portela y J. Castro Caldas (coords.) Portugal Chão. Oeiras: Celta editora, pp. 231247.

Prista, Marta Lalanda (2013). "Turismo e sentido de lugar em Óbidos: uma pousada como metáfora”. Etnográfica [Online] vol. 17 (2), pp. 369-392 http://etnografica.revues. org/3160 [Consultado el 28 de diciembre de 2017]

Setur, Secretaria de Turismo do Governo do Estado do Rio Grande do Norte (2018) "O Rio Grande do Norte". Secretaria de Turismo http://natalbrasil.tur.br/o-rio-grande-donorte/ [Consultado el 14 de mayo de 2018].

Silva, Anelino Francisco da (2001) "Migração e crescimento urbano: uma reflexão sobre a cidade de Natal". Scripta Nova - Revista Electrónica de Geografía y Ciencias Sociales 94 (74), Barcelona: Universidad de Barcelona. http://www.ub.edu/geocrit/sn-94-74.htm [Consultado el 23 de mayo de 2018]. 
Tamaso, Izabela (2005) "A expansão do patrimônio: novos olhares sobre velhos objetos, outros desafios... (Laudos culturais dos antropólogos inventariantes)". Sociedade e Cultura v. 8, n. 2, pp. 13-36.

Torquato, Rogério (2012) "Conheça um pouco da história do Carnaval e do Carnaval em Natal". Nominuto.com http://www.nominuto.com/noticias/ciencia-e-saude/conhecaum-pouco-da-historia-do-carnaval-e-do-carnaval-em-natal/82175/ [Consultado el 15 enero de 2018]. 